\title{
Bir Demir Yatağında Radyal Temelli Fonksiyon ve Ortalamasız Krigleme Kestirimlerinin Karşılaştırılması
}

\author{
Firat Atalay $^{1 *}$, M. Suphi Ünal ${ }^{2}$, S. Yasin Killıoglu ${ }^{3}$ \\ 1* Hacettepe Üniversitesi, Mühendislik Fakültesi, Maden Mühendisliği Bölümü, Ankara, Türkiye, (ORCID: 0000-0001-6349-7745), atalay@hacettepe.edu.tr \\ ${ }^{2}$ Hacettepe Üniversitesi, Mühendislik Fakültesi, Maden Mühendisliği Bölümü, Ankara, Türkiye, (ORCID: 0000-0002-9993-8300), msunal@hacettepe.edu.tr \\ ${ }^{3}$ Hacettepe Üniversitesi, Mühendislik Fakültesi, Maden Mühendisliği Bölümü, Ankara, Türkiye, (ORCID: 0000-0003-2227-9834), syasink@hacettepe.edu.tr
}

(İlk Geliş Tarihi 11 Nisan 2021 ve Kabul Tarihi 28 Ağustos 2021)

(DOI: 10.31590 /ejosat.913286)

\begin{abstract}
ATIF/REFERENCE: Atalay, F., Ünal, M. S., Kıllığlu, S Y. (2021). Bir Demir Yatağında Radyal Temelli Fonksiyon ve Ortalamasız Krigleme Kestirimlerinin Karşılaştırılması. Avrupa Bilim ve Teknoloji Dergisi, (27), 303-310.

\section{$\ddot{O} \mathbf{z}$}

Yakın geçmişte maden kaynaklarının kestirimi için ters uzaklık, en yakın komşu gibi yöntemler kullanılmakla birlikte, son dönemde maden yataklarının kestiriminde genellikle krigleme yöntemi kullanılmaktadır. Günümüzde kaynak kestiriminde kriglemeye alternatif yöntemler de gelişmektedir. Gelişmekte olan yöntemlerden birisi de Radyal Temelli Fonksiyon (RTF) ile kestirimdir. RTF gerçel değer alan bir $\phi$ 'nın değerinin bir girdi ve sabit noktaya göre değerinin radyal çekirdek değerine eşit olduğu fonksiyonlar olarak tanımlanırlar. $\mathrm{Bu}$ fonksiyonlar kullanılarak interpolasyon yapılabilir. RTF'ler ile interpolasyon birçok alanda kullanılmakla birlikte madencilikte henüz yaygın olarak kullanılmamaktadır. Ayrıca maden yatakları ile ilgili yapılan çalışmalarda ya RTF tek başına kullanılmış ya da RTF'nin özelleşmiş formları, krigleme ile karşılaştırılmıştır. Bu çalışmada, bir demir yatağında RTF kestirimleri ile krigleme kestirimleri karşılaştırılmıştır. Karşılaştırma amacı ile yataktaki demir tenörünün dağılımı öncelikle krigleme ile kestirilmiştir. Bu amaçla, variogramlar hesaplanmış ve bloklar üzerinden kestirimler yapılmıştır. Sonrasında ise RTF ile kestirim yapılmıştır. Kestirimde çekirdek fonksiyon olarak Gauss fonksiyonu tercih edilmiş ve fonksiyon $\alpha$ parametresi olarak 2,6 değeri kullanılmıştır. Elde edilen sonuçlar kestirimlerin özet istatistikleri, görsel ve trend analizleri yapılarak karşılaştırılmıştır.
\end{abstract}

Anahtar Kelimeler: Krigleme, Radyal temelli fonksiyon, Demir cevheri.

\section{Comparison of Radial Basis Function and Ordinary Kriging Estimations in an Iron Ore Deposit}

\begin{abstract}
While in the near past nearest neighbor and inverse distance methods have been used in mineral resource estimation, recently kriging became the dominant method. These days, new mineral resource estimation techniques are developed as alternatives to kriging. One of the alternative techniques developed is Radial Basis Functions (RBF). RBF can be defined as a real-valued function with the value of $\phi$ is used as input and this value is equal to radial kernel value. Interpolation can be performed by using these functions. While the use of the radial basis function is widely applied in many diverse areas, its usage in the mining industry is limited. Additionally, in the studies on mineral resources, RBF were either used solely or compared with kriging in a specialized form. In this study, estimations with RBF and kriging are compared in an iron ore deposit. For comparison, firstly, ore grade estimations are performed with kriging. For this purpose, variograms are calculated and block estimations are performed. Later, estimations are performed by using RBF. Gaussian kernel function is used for estimations and $\alpha$ value is selected as 2.6. Finally, summary statistics of the results were compared in terms of visual and trend analyses.
\end{abstract}

Keywords: Kriging, Radial basis function, Iron ore.

*Sorumlu Yazar: atalay@hacettepe.edu.tr 


\section{Giriş}

Maden kaynakları toplumlar için vazgeçilmez unsurlardır. Her maden potansiyelinin maden kaynağına dönüşmesi ise mümkün değildir. Bir maden potansiyelinin maden kaynağına dönüşmesi için öncelikle güncel ekonomik ve teknik koşullar altında karlı bir şekilde üretilmesi gerekir. Maden kaynaklarının karlılığının belirlenmesinde en önemli unsurlardan birisi ise kalite değişkeni değerleridir. Birçok cevherde kalite değişkeni tenör olarak adlandırılır ve bir cevherleşmede ekonomik değer teşkil eden cevher miktarının toplam kütledeki oranı olarak tanımlanabilir. Maden kaynaklarında konumsal olarak tenör/kalite değişkeni sabit olmayıp konuma bağlı olarak değişkenlik gösterir. Tenörün konumsal dağılımın belirlenmesi ilgili maden yatağının ekonomik olup olmamasının kararının verilmesinde en önemli unsurdur. Bir maden kaynağında tenör dağılımının belirlenmesi ekonomikliğe ek olarak maden üretim yönteminin belirlenmesinde de önemli bir rol oynar. Örneğin bazı durumlarda cevherleşmenin yeryüzüne yakın olması durumunda açık ocak ile üretim yapılabilir. Bu gibi durumlarda ekonomik sebepler ile maden kaynağı işletilmeye tenörün en yüksek olduğu kısımdan başlanabilir. Bu gibi sebepler yüzünden yer bilimlerinde tenör dağılımın ortaya konulması geniş ve önemli bir yer tutmaktadir.

Maden kaynaklarında tenör dağılımının belirlenebilmesi için genellikle sahada sondajlar yapılır. Sondaj işlemi zahmetli, zaman alan ve görece pahalı bir süreçtir. Maden kaynağındaki tenör yayılımını bulmak için yapılan bu sondajlar sonucunda kaynaktan toplanan örnekler ile ilgili maden kaynağının kütlesi arasındaki oran yaklaşık olarak milyarda birdir (Rossi ve Deutsch, 2013). Görüldüğü gibi maden kaynağının tenör yayılımını ortaya koymak için son derece kısıtlı miktarda veri toplanmaktadır. $\mathrm{Bu}$ sebeple kısıtlı veriye dayanarak konumsal tenör değişkenliğinin tahmin edilebilmesi için birçok yöntem geliştirilmiştir (Tutmez vd., 2009). Bu yöntemlerden en sık kullanılanları en yakın komşu, ters uzaklık ve krigleme yöntemleridir. Bu yöntemlerden en yakın komşu yöntemi, ilgili maden bloğunun kalite değişkeni değerinin en yakın veriye eşit olduğunu kabul eder. Ters uzaklık yönteminde ise verilerin kestirimi, işlemin yapılacağı blok üzerindeki verilerin ağırlığının uzaklığın tersi ile ilişkili olduğu varsayımına dayanır ve ağırlıklar buna göre belirlenir. Krigleme ise, variogram modelleme ve kestirim adımları olmak üzere iki adımdan oluşan bir kestirim yöntemidir. İlk adımda uzaklığa bağlı ilişki deneysel variogram değerlerinden yararlanılarak variogram modelleri uyarlanır. İkinci adımda ise uyarlanan bu variogram modelleri kullanılarak kestirim yapılır. Birçok maden kaynağındaki kalite değişimi bu yöntemler kullanılarak yapılmıştır. Örneğin kömür yataklarında krigleme yöntemi oldukça sık bir şekilde kullanılmaktadır (Afzal, 2018; Dag ve Ozdemir, 2013; Gül ve Küçükkarasu, 2020; Hatton ve Fardell, 2012; Jeuken vd., 2020; Marwanza vd., 2019; Nielsen vd., 2019; Siddiqui vd., 2015; Tercan ve Karayigit, 2001; Whateley vd., 1997; Zhang vd., 2013). Krigleme kömür yataklarına ek olarak birçok altın, demir, bakır, kobalt, nikel yataklarında ve bazı sedimanter yataklarda da sıkça kullanılan bir yöntemdir (Afzal, 2018; Bargawa vd., 2020; Cornell ve Schwertmann, 2003; De-Vitry vd., 2007; Elevli vd., 2018; Gusman vd., 2019; Santos ve Yamamoto, 2019; Wadi ve Ivanik, 2019; J. Wang vd., 2018; Zerzour vd., 2021; Zhang vd., 2021). Ayrıca bazı çalışmalarda ise hem krigleme hem de ters uzaklık yöntemlerinin bir arada kullanıldığı görülebilmektedir (Afzal, 2018; Shahbeik vd., 2014; S. Wang vd., 2017).
Yukarıdaki örneklerden de görüldüğü gibi bu yöntemler arasında en sık kullanılan yöntem kriglemedir. Krigleme yöntemi, kestirim için gerekli olan denklemlerin hata varyanslarının en düşük olacağı şekilde oluşturulması ve yansızlık koşulunun sağlanması sonucunda (yönünden) güçlü bir yöntemdir (Yünsel, 2007). Ancak krigleme durağanlık varsayımına dayandığından tenörün yöne bağlı sürekli artış ya da azalış içinde bulunmasını varsaymaktadır (Yünsel, 2019). Bu sebepten öncelikle durağanlık varsayımı test edilmelidir. Sonrasında ise tenör değişkenliğinin yöne bağlı değişkenliğinin ortaya koyulabilmesi için farklı yönlerde variogramların hesaplanması ve bu deneysel variogramlara model variogramlar uyarlanması gerekir. Variogram uyarlama işlemi zahmetli ve tecrübeye dayalı bir işlemdir. Ayrıca bazı durumlarda variogramın hesaplanması mümkün olmamaktadır (Bargawa ve Tobing, 2020). $\mathrm{Bu}$ sebepten variogram uyarlaması görecelidir ve konu hakkında uzman kişilere ihtiyaç duyulur. Ters uzaklık yönteminde ise tenör değerlerinin uzaklığın tersi ile ikinci ya da üçüncü dereceden ilişkili olduğu düşünülerek kestirimler yapılır. Ancak ilişkinin derecesinin belirlenmesi çoğu zaman keyfi olarak yapılır ve dayanağı yoktur. Bazı durumlarda, özellikle cevher yatağı sınırlarında, elde edilen kestirim değerleri doğada bulunamayacak kadar keskin değişiklikler gösterebilir. En yakın komşu kestiriminde ise kestirim değeri en yakın sondaj değeri olarak belirlendiğinden kestirim sonuçları çoğu zaman gerçekçi değildir.

Görüldüğü gibi sıkça kullanılan tenör kestirim yöntemlerinin bazı dezavantajları olması sebebi ile mevcut yöntemlere alternatif yöntemler de geliştirilmektedir. Geliştirilmekte olan yöntemlerden birisi de Radyal temelli fonksiyon (RTF) yöntemidir (Wright, 2003). Adından da anlaşılabileceği gibi RTF ile kestirimde Radyal temelli fonksiyonlar kullanılır. Diğer yöntemlerde olduğu gibi mevcut veriler kullanılarak tenör dağılımı kestirilir. Kriglemede olduğu gibi konumsal ilişkiyi ölçen variogram gibi bir ek fonksiyonun hesaplanmasına ve tahmin edilmesine ihtiyaç duyulmamaktadır. RFT kullanılarak maden kaynak kestiriminin yapıldı ̆̆ çalışmalar da mevcuttur (Samanta, 2010; Santos ve Yamamoto, 2019; Wang vd., 2018). Bu çalışmalarda RTF kullanılarak cevher tenör dağılımları ve cevher sürekliliği kestirilmiştir. RTF'lerin doğrudan kestirimde kullanıldığı çalışmalar görece yeni ve kısıtlıdır. Bu sebepten RTF'lerin kullanılarak kaynak kestiriminin yapıldığ çalışmalara ihtiyaç vardır. Bu çalışmanın amacı RTF ile Krigleme yöntemlerinin bir demir yatağında tenör kestirimleri yapılarak kıyaslanmasıdır. Bu amaçla öncelikle demir yatağındaki demir cevherinin yayılımı modellenmiş ve katı model oluşturulmuştur. Daha sonrasında sadece katı model içerisinde kalan veriler kompozitlenmiş ve bu kompozitler üzerinden variogramlar hesaplanmıştır. Hesaplanan variogramlar kullanılarak model variogram uyarlanmış ve krigleme ile kestirim yapılmıştır. Daha sonrasında ise kestirimler RTF ile tekrarlanmıştır. Kestirim için Gauss çekirdek fonksiyonu kullanılmıştır. Sonuçlar kestirimlerin özet istatistikleri, görsel ve trend analizleri yapılarak karşılaştırılmıştır.

\section{Materyal ve Metot}

\subsection{Ortalamasız Krigleme}

Krigleme yöntemi, ölçümü yapılan konumlardaki değişkenlerden yola çıkarak ölçümü yapılmamış konumlardaki değişkenin değerini kestiren bir yöntemdir. Kriglemede kestirimler en iyi doğrusal yansız kestirim koşullarını yerine getirecek şekilde yapılır. Krigleme işlemi için öncelikle deneysel 
variogramın hesaplanması gerekir (Journel ve Huijbregts, 1978) (Denklem 1).

$$
\gamma(h)=\frac{1}{2 N(h)} \sum_{i=1}^{n}\left(x_{i}-x_{i+h}\right)^{2}
$$

Burada; $\gamma(\mathrm{h})$ deneysel variogram değerini, $\mathrm{N}(\mathrm{h})$ variogram hesabında kullanılan çift sayısını, $x_{i}$ ve $x_{(i+h)}$ ise sırası ile $i$ konumundaki ve $\mathrm{i}+\mathrm{h}$ konumundaki ölçüm değerlerini ifade eder.

Denklem 1'de görüldüğü gibi deneysel variogramlar belirli ve sonlu sayıdaki uzaklıklar üzerinden hesaplanır (Yaylagul ve Tutmez, 2020). Tüm uzaklıklardaki variogram değerlerine ise deneysel variogramlar kullanılarak model variogramın uyarlanması ile ulaşılır. Madencilikte en sık kullanılan yuvalı yapıya sahip Gauss variogram modeli Denklem 2'de gösterilmiştir.

$$
\gamma(h)=C_{o}+C *\left[\frac{3}{2} \frac{h}{a}-\frac{1}{2}\left(\frac{h}{a}\right)^{3}\right]
$$

Burada; $\mathrm{C}_{\mathrm{o}}$ külçe etki değerini, $\mathrm{C}$ variogram modeline ait eşik değeri, a yapısal uzaklığı ve h ise uzaklığ 1 ifade etmektedir.

Variogram modelinin de uyarlanması ile krigleme için gerekli olan tüm uzaklıklardaki variogram değerlerine ulaşılmış olur. Krigleme ile kestirimde her bir değerin kestirim noktasındaki ağırlı̆̆ı Denklem 3'te olduğu gibi hesaplanabilir (Matheron, 1963; Tercan ve Karayigit, 2001).

$$
z\left(x_{o}\right)=\sum_{i=1}^{n} \lambda_{i} * z\left(x_{i}\right)
$$

Denklem 3 'te; $\mathrm{z}\left(\mathrm{x}_{\mathrm{o}}\right)$ kestirilmek istenen noktayı, $\lambda_{\mathrm{i}}$ kestirimde kullanılacak olan ölçüm değerinin ağırlığını ve $\mathrm{z}\left(\mathrm{x}_{\mathrm{i}}\right)$ ise kestirimde kullanılacak ölçüm değerini belirtir. Burada kestirim ağırlıkları olan $\lambda_{\mathrm{i}}$ değerinin belirlenmesi en önemli noktadır ve krigleme yönteminde ağırlıklar aşağıdaki denkleme göre hesaplanır (Denklem 4).

$$
\left\{\begin{array}{c}
\sum_{i=1}^{n} \lambda_{i} * z\left(x_{i}\right)+\mu=\gamma\left(x_{i}, x_{0}\right) \\
\sum_{i=1}^{n} \lambda_{i}=1
\end{array}\right.
$$

Burada; $\mu$ lagrange çarpanını, $\gamma\left(\mathrm{x}_{\mathrm{i}}, \mathrm{x}_{0}\right)$ ise kestirilecek nokta ile kestirimde kullanılacak ölçüm arasındaki variogram değerini ifade eder. Denklem 4'te görüldüğü gibi kestirimde kullanılan ağırlıkların toplamı 1'e denk gelmektedir. Bu kriglemenin yansızlık koşulunun sağlanmasına neden olur.

\subsection{Radyal Temelli Fonksiyon}

Bu çalışmada, radyal temelli fonksiyon olarak adlandırılacak olan ve İngilizcesi "radial basis function" olan fonksiyon, bilinmeyen bir fonksiyonun bilinen verilerden yola çıkarak tahmin edilmesine yarar. "Radial basis function" dilimize radyal temelli fonksiyon ve yarıçapsal temelli fonksiyon olarak da çevrilmiştir. RTF gerçek bir değer alan $\alpha$ 'nın değeri olan $\alpha(\mathrm{x})$ 'in sabit bir nokta ile girdi noktası arasındaki uzaklığa bağlı olan bir fonksiyonuna eşit olması yani diğer bir ifadeyle $\alpha(\mathrm{x})$ olmasıdır. $\mathrm{Bu}$ eşitliği sağlayan tüm fonksiyonlar radyal fonksiyon olarak adlandırılır. Radyal temelli fonksiyonlar s $\alpha:[0, \sim) \rightarrow \mathrm{R}$ aralığında tanımlıdır. Metrik vektör uzayında bir fonksiyon $\alpha(\mathrm{c})=\alpha(\mathrm{x}-\mathrm{c}) \mathrm{c}$ noktasında merkezi olan bir radyal çekirdek olarak adlandırılır. $\mathrm{Bu}$ radyal fonksiyon ve ilişkili radyal çekirdeklerin bir arada kullanılması ile RTF'lere ulaştırılır.

Radyal temelli fonksiyonlarda s1klıkla kullanılanlar Tablo 1 'de verilmiştir.

Tablo 1. RTF'ler

\begin{tabular}{lc}
\hline $\begin{array}{l}\text { Radyal temelli } \\
\text { Fonksiyon }\end{array}$ & İşlemci \\
\hline Gauss & $e^{-(c r)^{2}}$ \\
Polyharmonic Spline & $R^{2 k-1}$ \\
Multiquadrics & $\sqrt{r^{2}+c^{2}}$ \\
Ters Multiquadrics & $\frac{1}{\sqrt{r^{2}+c^{2}}}$ \\
Ters Quadratic & $\frac{1}{r^{2}+c^{2}}$ \\
\hline
\end{tabular}

Tablo 1'de c, k, R değerleri fonksiyonların aldığı değerleri ve davranışlarını belirleyen parametrelerdir.

\subsection{Radyal Temelli Fonksiyon ve Kestirim}

Kriglemeye benzer şekilde radyal temelli fonksiyon ile kestirim de denklem 3'te olduğu gibi kestirimde kullanılan verilere ağırlıkların atanmasına dayanır. Tek değişen kestirim değerleri olan $\mathrm{z}\left(\mathrm{x}_{\mathrm{i}}\right)$ yerine çekirdek fonksiyon olan $\phi(\|.\|$.$) işlemcisinin kullanılması ve f interpolantina eşitlenmesidir$ (Denklem 5).

$$
\sum_{i=1}^{n} \lambda_{i} * \emptyset\left(\left\|x_{i}-x_{0}\right\|\right)=f
$$

$\mathrm{Bu}$ durumda oluşacak olan matris denklemi aşağıda verilmiştir (Wright, 2003).

$$
\left[\begin{array}{cccc}
\emptyset\left(\left\|x_{1}-x_{1}\right\|\right) & \emptyset\left(\left\|x_{2}-x_{1}\right\|\right) & \ldots & \emptyset\left(\left\|x_{n}-x_{1}\right\|\right) \\
\varnothing\left(\left\|x_{1}-x_{2}\right\|\right) & \varnothing\left(\left\|x_{2}-x_{2}\right\|\right) & \ldots & \emptyset\left(\left\|x_{n}-x_{2}\right\|\right) \\
\vdots & \vdots & \ldots & \vdots \\
\varnothing\left(\left\|x_{1}-x_{n}\right\|\right) & \emptyset\left(\left\|x_{2}-x_{n}\right\|\right) & \ldots & \emptyset\left(\left\|x_{n}-x_{n}\right\|\right)
\end{array}\right]\left[\begin{array}{c}
\lambda_{1} \\
\lambda_{2} \\
\vdots \\
\lambda_{n}
\end{array}\right]=\left[\begin{array}{c}
f\left(x_{1}\right) \\
f\left(x_{2}\right) \\
\vdots \\
f\left(x_{n}\right)
\end{array}\right]
$$

Denklem 6'da $\emptyset$ kestirimde kullanılacak olan tüm değerlerin uzaklıklarının kullanılan çekirdek fonksiyondaki değerini, $\mathrm{f}(\mathrm{x})$ ise fonksiyonun ilgili uzaklıktaki aldığı değeri ifade eder. Buna göre matriks denkleminin tüm $\lambda$ 'lar yani kestirimde kullanılacak olan tüm ağırlıklar için çözülmesi ile denklem 7'de olduğu gibi kestirim işlemi gerçekleştirilir.

$$
z\left(x_{o}\right)=\sum_{i=1}^{n} \lambda_{i} * z\left(x_{i}\right)
$$

Görüldüğü gibi kriglemede ağırlıkların atanmasında variogram fonksiyonu kullanılırken, radyal temelli fonksiyon ile kestirimde ise variogramın yerini radyal temelli fonksiyon almıştır. 
Radyal temelli fonksiyonların kestirim aralığg teorik olarak ($\infty$ ve $+\infty$ ) aralığındadır (Skala vd., 2020).

Maden kaynakları teorik olarak $(0,+\infty)$ aralığında değerler alır. Bilindiği gibi radyal temelli fonksiyonlar ile kestirim negatif değerlerde alabileceğinden maden kaynaklarının kestiriminde doğrudan kullanılmaları durumunda pozitif tanımlılığı garanti etmezler (Myers, 1992). Ayrıca her ne kadar maden kaynakları teorik olarak sonsuz değerler alabilse de pratikte bu durum her zaman geçerli olmayabilir. Çoğu maden varlığı yüzde cinsinden ölçülür ve bu sebepten $[0,100]$ aralığında değer alırlar. $\mathrm{Bu}$ sebeplerden dolayı RTFlerin maden yatak kestiriminde kullanılması amacıyla teorik ve pratik arasındaki uyumsuzluğun giderilebilmesi için koşullandırma yapılmasına ihtiyaç vardır.

\subsection{Koşullandırılmış Radyal Temelli Fonksiyon}

RTF ile kestirim maden kaynaklarının sonuçlarından beklenen pozitif tanımlılık ve sonuçlarının istenen aralıklarda olması koşullarını garanti etmediğinden "koşullandırılmış radyal temelli fonksiyonlar ile kestirim” yaklaşımı geliştirilmiştir. Bu yaklaşımın klasik yöntemden temel olarak iki farklılığı vardır. İlk farklılık, kestirimde tüm veriler yerine kestirim noktasına komşuluk eden belirli sayıda en yakın noktalar kullanılır. Böylece bu koşullandırma ile kestirim sonuçlarının daha tutarlı olması sağlanmıştır. Yöntemin adındaki koşullandırma kelimesi bu adımdan gelir. $\mathrm{Bu}$ adım da istenen sonuçlara ulaşılmasını garanti etmez. Koşullandırma işleminden sonra hedef nokta için kestirim işlemi gerçekleştirilir ve kestirim değerinin istenen aralıklarda olup olmadığına bakılır. Kestirimin istenen aralıkta olmaması durumunda çekirdek fonksiyondaki ilgili parametre olan $\alpha$ parametresi $[0,+\infty)$ aralığında olmak üzere ve sıfirdan başlamak koşulu ile yeni bir kestirim işlemi gerçekleştirilir. $\mathrm{Bu}$ işlemin sonucu da yeniden koşulu sağlayıp sağlamadığı üzerine test edilir. Eğer sağlamıyorsa $\alpha$ parametresi arttırılarak testlere devam edilir. Kestirim sonucunun istenen aralıkta çıkması durumunda elde edilen değer kestirim sonucu olarak kabul edilir. Koşullandırılmış radyal temelli fonksiyon ile kestirimin adımları Tablo 2'de verilmiştir.

Tablo 2. Koşullandırılmış radyal temelli fonksiyon ile kestirim adımları

\begin{tabular}{|c|c|}
\hline Adım & İşlem \\
\hline 1 & $\begin{array}{l}\text { Kestirim için radyal çekirdek fonksiyonunun ve ilgili } \\
\text { parametrelerin belirlenmesi }\end{array}$ \\
\hline 2 & Kestirim aralığ $1\left[a_{1}, a_{2}\right]$ belirlenmesi \\
\hline 3 & $\begin{array}{l}\text { Kestirilecek olan maden bloğunun orta noktası dikkate } \\
\text { alınarak bu bloğa komşu olan verilerin bulunması }\end{array}$ \\
\hline 4 & Kestirim değerinin Denklem 7 kullanılarak belirlenmesi \\
\hline 5 & $\begin{array}{l}\text { Kestirim değerinin }\left[\mathrm{a}_{1}, \mathrm{a}_{2}\right] \text { dışında olması durumunda } 1 \text {. } \\
\text { Adıma geri dönülerek çekirdek fonksiyondaki } \\
\text { parametrenin değiştirilmesi. Bu adım kestirim değeri }\left[\mathrm{a}_{1} \text {, }\right. \\
\left.\mathrm{a}_{2}\right] \text { aralığında çıkana kadar devam ettirilir. }\end{array}$ \\
\hline
\end{tabular}

\section{Demir Yatağının Kestirimi}

Kestirim yöntemlerinin kıyaslanması amacı ile Türkiye'deki bir demir yatağı kullanılmıştır. Bu demir yatağında demir cevheri yoğunlukla manyetit ve hematit olup, Fe değerleri ise yüzde (\%) cinsindendir. Sahadaki cevherleşme metamorfitlere ait şist, e-ISSN: 2148-2683 kalkşist ve mermerleri kesen siyenit porfirlerin oluşturduğu kontakt zonlarda ve şistlerin geçirgen olmaması nedeniyle özellikle mermerler içinde gelişmiştir. Cevherleşme kuşağı DoğuBatı doğrultusunda ve 900 metre uzunluğundadır. Damar tipi cevherleşmelerin kalınlıkları 1-2 metre, skarn tipinde ise 2-4 metre arasında değişir. Skarn tipi cevherleşmede cevherleşmenin şekli yığın, mercek şeklindedir. Sahada cevher minerali olarak çokluk sırasına göre manyetit, hematit, limonit ile pirit, pirotin ve kalkopirit tespit edilmiştir. Oksidasyon minerali olarak bakırlı zonlarda malahit ve azurit görülür. Gang minerali olarak silis, epidot ve kalsit izlenir.

Sahada toplam 58 adet sondaj yapılmış olup sondajların tamamı yüzeye diktir. Toplam sondaj uzunluğu 13463 m'dir. Bu sondajların en kısası $74 \mathrm{~m}$ iken en uzun sondaj $371 \mathrm{~m}$ derine kadar inmektedir. Sondajların ortalama derinliği ise yaklaşık olarak 232 m'dir. Sondajlar yaklaşık olarak $9000 \mathrm{~m}^{2}$ 'lik bir alana yayılmakla birlikte sondajlar arası ortalama mesafe $30 \mathrm{~m}$ 'dir. Sondajların yayılımı Şekil 1'de gösterilmiştir.

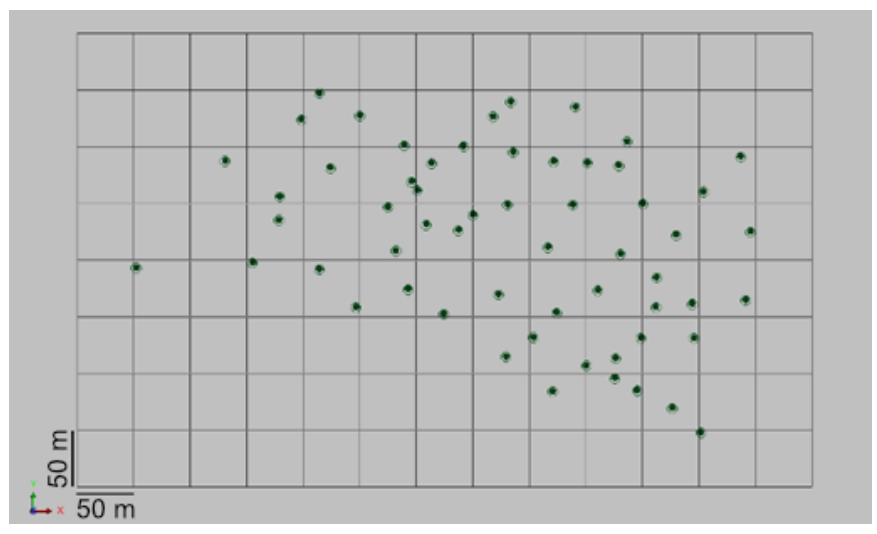

Şekil 1. Sondajların plan görüntüsü

Sondajlarda tüm birimler için Fe ölçümleri yapılmış olup bu ölçümlerden cevherleşmenin yaygın olduğu kısımlardaki özet istatistikler Tablo 3'te verilmiştir.

\section{Tablo 3. Fe analizleri özet istatistikleri}

\begin{tabular}{llllll}
\hline $\begin{array}{l}\text { Veri } \\
\text { sayısı }\end{array}$ & $\begin{array}{l}\text { En } \\
\text { düşük }\end{array}$ & Ortalama & Ortanca & $\begin{array}{l}\text { En } \\
\text { yüksek }\end{array}$ & $\begin{array}{l}\text { Standart } \\
\text { Sapma }\end{array}$ \\
\hline 777 & 1,34 & 32,28 & 33,7 & 60,7 & 12,21 \\
\hline
\end{tabular}

Tablo 3'te görüldüğü gibi oldukça düşük değerler mevcut olup bu durum sahada tüm alanın cevher yönünden zengin olmadığını gösterir. $\mathrm{Bu}$ sebepten yatakta maden kaynak kestirimine uygun ve cevherleşmenin yüksek olduğu alanın belirlenmesi gerekir. Cevher yayılımını belirlemek için sahada çeşitli yönlerden kesitler alınmıştır. Alınan bu kesitler birleştirilerek 3 boyutlu cevher yatağı modeli oluşturulmuştur. Oluşturulan model Şekil 2'de gösterilmiştir. 


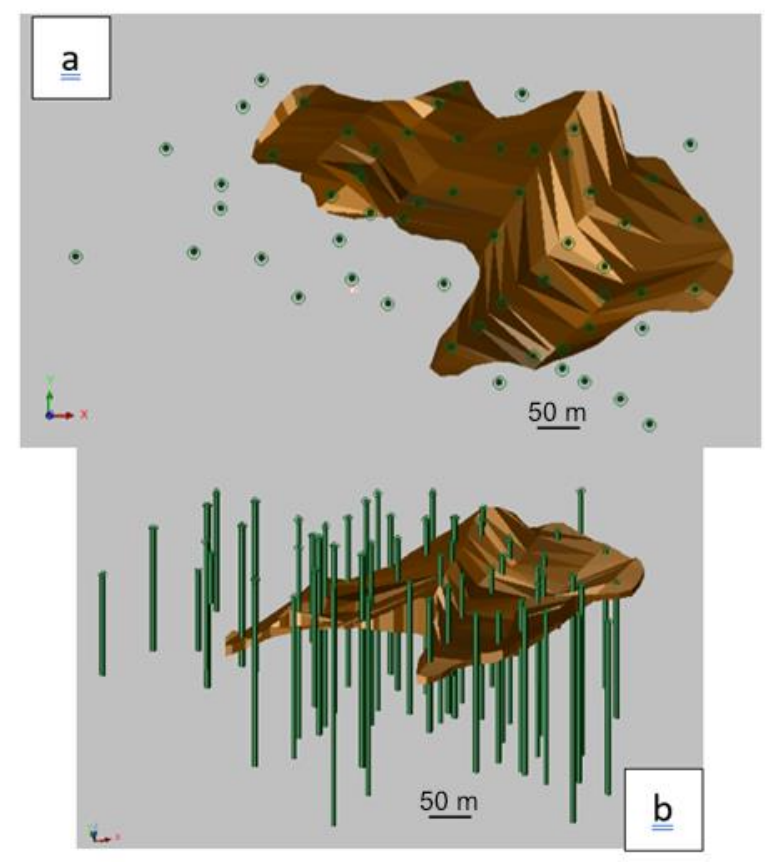

Şekil 2. Katı model ve sondaj görüntüleri a) plan b) oblik

Şekil 2'de görüldüğü gibi yatak, kuzeybatı yönünde 35॰'lik belirgin.bir eğime sahiptir. Şekil 2.a'da görüldüğü gibi, bazı sondajlar katı model yapılırken dikkate alınmamıştır. Bunun sebebi bu sondajlarda ya hiç cevherli birimlerin kesilmeyişi ya da cevherli birimlerin kalınlığının az olması sebebi ile cevher zonu oluşturmamasıdır. Katı modelin toplam hacmi 1,7 milyon $\mathrm{m}^{3}$ 'tür. Kestirimde kullanılmak üzere ham verilerin $1 \mathrm{~m}$ uzunluğunda kompozitleri oluşturulmuştur. Kestirimlerde bu kompozitler kullanılacağından katı model içerisinde kalan verilerin özet istatistikleri ve histogramları sırası ile Tablo 4 ve Şekil 3 'te verilmiştir.

Tablo 4. Katı model içerisinde kalan kompozitlerin özet istatistikleri

\begin{tabular}{llllll}
\hline $\begin{array}{l}\text { Veri } \\
\text { sayısı }\end{array}$ & $\begin{array}{l}\text { En } \\
\text { düşük }\end{array}$ & Ortalama & Ortanca & $\begin{array}{l}\text { En } \\
\text { yüksek }\end{array}$ & $\begin{array}{l}\text { Standart } \\
\text { Sapma }\end{array}$ \\
\hline 850 & 10,27 & 30,96 & 31,55 & 60,4 & 11,77 \\
\hline
\end{tabular}

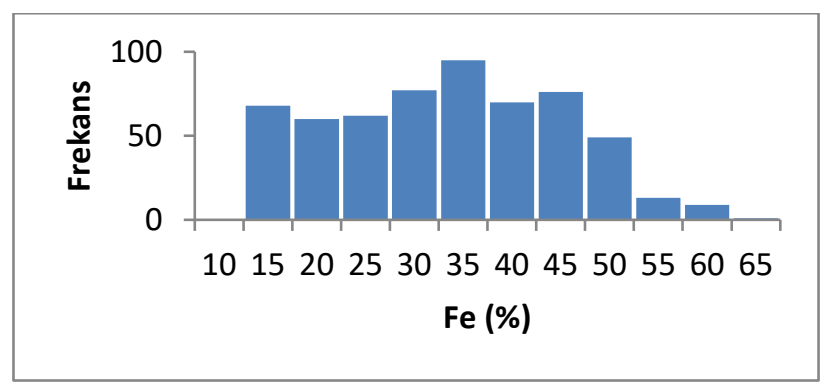

Şekil 3. Katı model içerisinde kalan kompozitlerin dağılımı

Tablo 3 ile Tablo 4 karşılaştırıldığında veri sayısının arttığı gözlenmektedir. Bu durum bazı verilerin $1 \mathrm{~m}$ 'den uzun örnekler halinde toplanmasından kaynaklanmaktadır. Benzer şekilde görece verilerin varyansı da aynı sebepten düşmüştür. En düşük değerin yükselmesinin sebebi ise cevher olarak tanımlanan ancak katı model içerisinde bulunmayan düşük tenörlerden kaynaklıdır.

Maden kaynak kestirimleri doğrudan katı modeller üzerinden yapılmamaktadır. Kestirimlerin yapılabilmesi için katı modeli e-ISSN: 2148-2683 temsil eden blok modellere ihtiyaç duyulmaktadır. Kestirim amacı ile sahada $X, Y$ ve $Z$ yönünde boyutları $10 \times 10$ ve $5 \mathrm{~m}$ olan blok model oluşturulmuştur. Oluşturulan blok model Şekil 4'te gösterilmiştir.

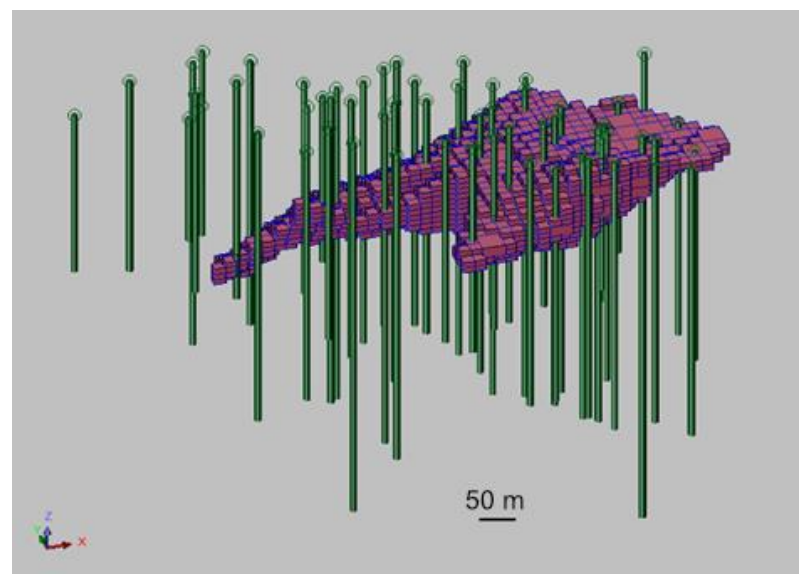

Şekil 4. Blok model oblik görüntüsü

Şekil 4'te görüldüğü gibi blok model katı modeli temsil eder niteliktedir ve 3400 adet blok mevcuttur. Kestirimler bu bloklar üzerinden yapılacaktır. Blok modelin oluşturulması ile kestirimlerin yapılması ve kıyaslanması adımlarına geçilmiştir.

Krigleme ile kestirim amacı ile deneysel variogramlar hesaplanmış ve bu deneysel variogramlara model variogramlar uyarlanmıştır. Yatak yatay yönde izotrop davranırken düşey yönde değişkenlik daha yüksektir. Model uyarlaması sonucu oluşan variogram değerleri Tablo 5'te verilmiştir. Uyarlanan model küreseldir.

Tablo 5. Uyarlanan variogram modeli

\begin{tabular}{llll}
\hline $\mathbf{C}_{\mathbf{0}}$ & $\mathbf{C}$ & $\mathbf{a}_{\text {yatay }(\mathbf{m})}$ & $\mathbf{a}_{\text {düșey }(\mathbf{m})}$ \\
\hline 28 & 268 & 150 & 9 \\
\hline
\end{tabular}

Co: külçe etkisi, C: eşik değer, a: yapısal uzaklık

Tablo 5'te verilen variogram modeli kullanılarak yataktaki Fe değerleri tek seferde kestirilmiştir. Kestirim sonucu elde edilen Fe değerlerinin blok modeldeki görüntüsü Şekil 5 'te gösterilmiştir. 


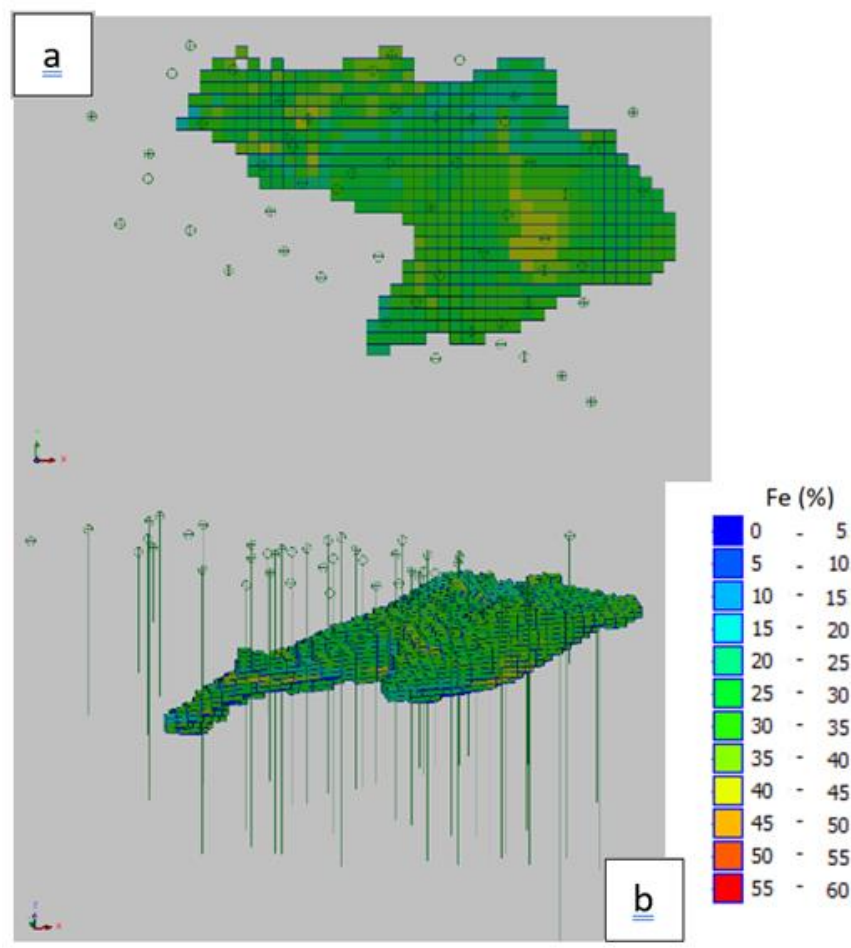

Şekil 5. Krigleme sonucu elde edilen blok model a) plan b) oblik

Şekil 5’te görüldüğü gibi yatağın en uç kısmına tekabül eden batı kısmında tenörler diğer kısımlara göre daha düşüktür. Ayrıca tenör düşüklüğü güney kısımlarda görece biraz daha düşüktür.

Krigleme ile kestirim işleminden sonra RTF temelli kestirim işlemine geçilmiştir. $\mathrm{Bu}$ amaçla deneme yanılma yöntemi kullanılarak alfa değeri 2,6 olarak belirlenmiştir. Farklı alfa değerleri incelenmiş ve bu değerlerden ham verilerin özet istatistiklerine en çok benzeyen blok model sonuçlarının elde edildiği değer kestirim işlemi için tercih edilmiştir. Buna göre RTF sonucunda elde edilen blok model görüntüsü Şekil 6'da sunulmuştur.

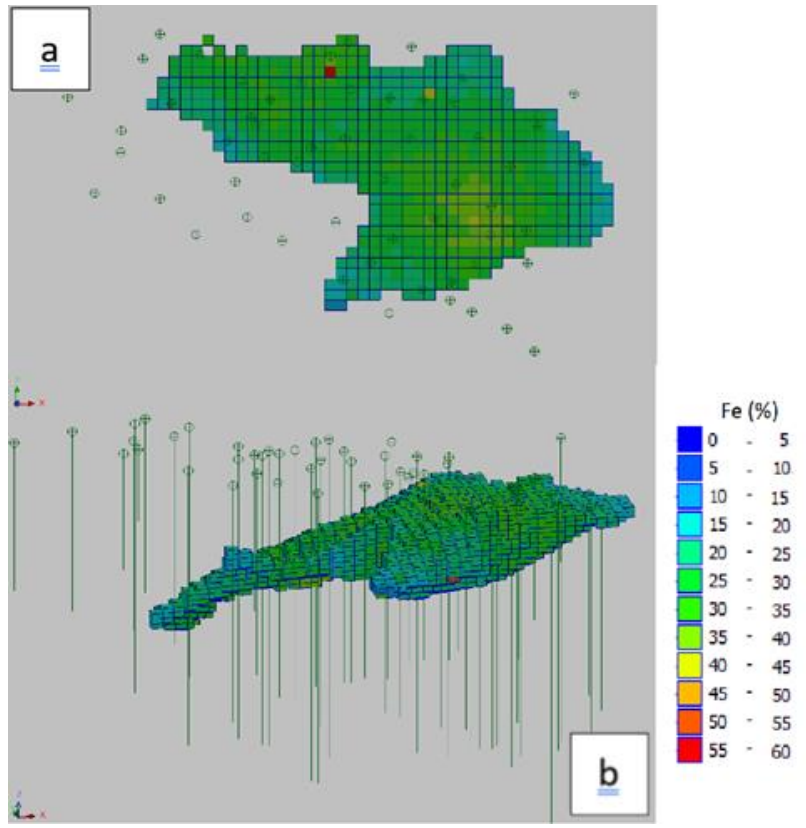

Şekil 6. RTF ile kestirim sonucu elde edilen blok model a) plan b) oblik
Şekil 6'da görüldüğü gibi yatak sınırlarına doğru tenör azalmaktadır. Şekil 5 ve 6 kıyaslandığında sonuçların birbirine görsel olarak benzer olmakla birlikte yer yer farklilıklar göze çarpmaktadır. Örneğin kriglemede yatağın orta noktalarına denk gelen kısımda yüksek tenörlü alan daha fazla alan kaplarken bu durum RTF ile kestirimde daha düşük bir alana denk gelmektedir. Ayrıca RTF'de görülen yatak sınırlarına doğru tenör azalması krigleme ile kestirimde belirgin değildir.

Karşılaştırma amaçlı olarak krigleme ve RTF temelli yöntem ile kestirilen bloklar ile kompozitlerin özet istatistikleri Tablo 6'da verilmiştir.

Tablo 6. Kompozit, krigleme ve RTF özet istatistikleri

\begin{tabular}{lrrr}
\hline & Kompozit & Krigleme & \multicolumn{1}{c}{ RTF } \\
\hline Veri sayısı & 850 & 3415 & 3415 \\
En düşük & 10,27 & 18,27 & 12,05 \\
Ortanca & 31,55 & 27,82 & 29,00 \\
Ortalama & 30,96 & 31,22 & 29,98 \\
En yüksek & 60,4 & 44,66 & 55,88 \\
Standart sapma & 11,77 & 5,28 & 4,56 \\
\hline
\end{tabular}

Özet istatistikler incelendiğinde hem krigleme hem de RTF temelli kestirimde elde edilen sonuçların ortalamasının kompozitlerin ortalamasına yakın olduğu görülmektedir. Ancak kestirim değerlerinin en düşük ve en yüksek değerleri incelendiğinde RTF ile yapılan kestirimlerin kompozitlere daha yakın olduğu gözlenmektedir.

Özet istatistiklere ek olarak Sağa (X), Yukarı (Y) ve Kot yönlerinde kestirimler ve kompozitlerin değişimini karşılaştırmak için trend analizleri yapılmıştır. $\mathrm{Bu}$ analizler ile yöne bağlı değişim ortaya koyulmaktadır (Rossi ve Deutsch, 2013). Yöne bağlı değişimler Şekil 7'de gösterilmiştir.

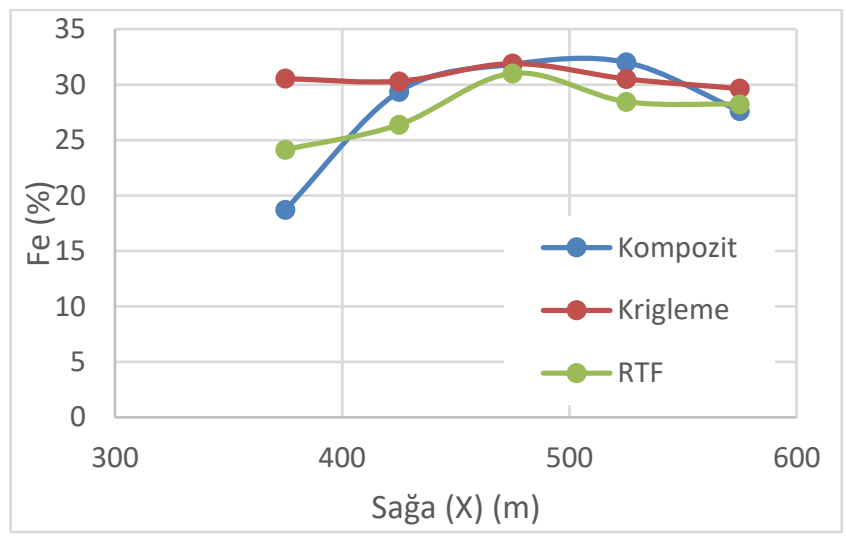



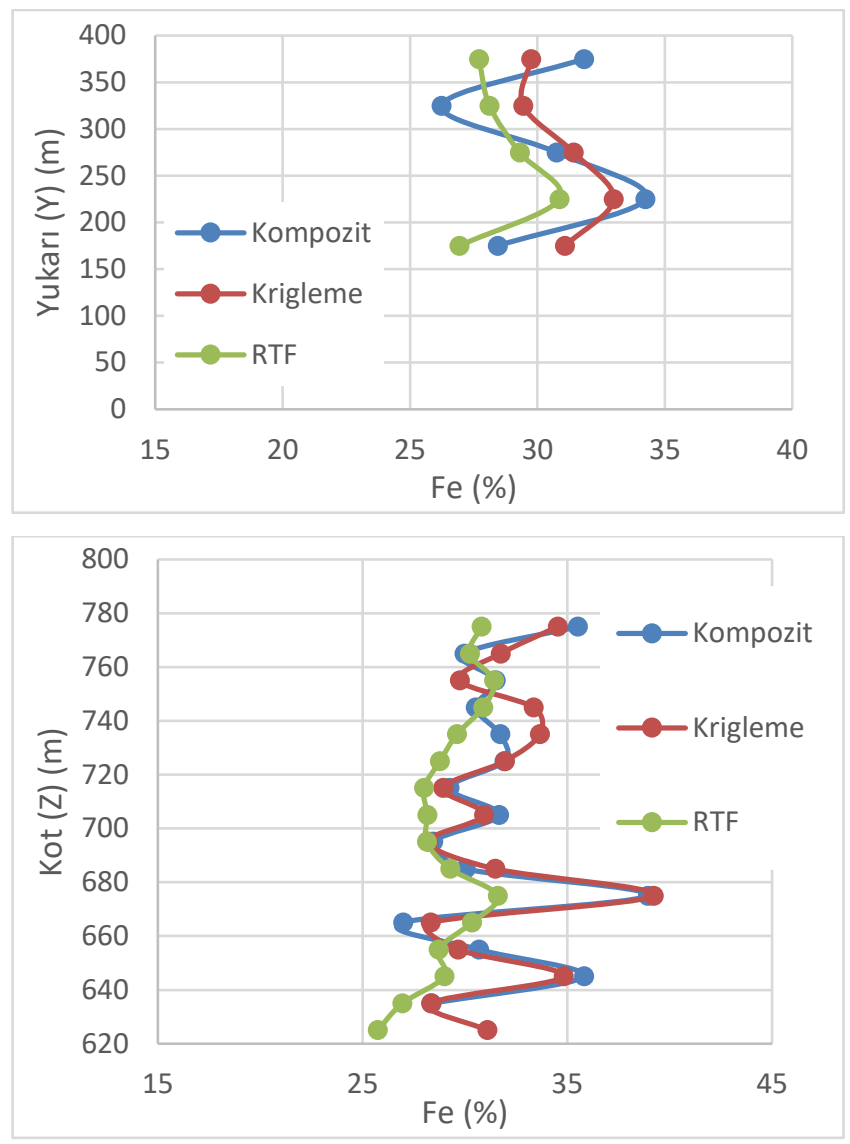

Şekil 7. Trendler;a) Săga (X),b) Yukarı (Y) ve c) Kot (Z)

Şekil 7'de görüldüğü gibi ve genel olarak beklendiği üzere her iki kestirimin de kompozitlere göre değişkenlikleri daha düşüktür ve ortalama etrafında değerler üretilmiştir. Trend analizleri incelendiğinde RTF ile üretilen kestirimler kompozitlere göre bazı bölgelerde yüksek bazı bölgelerde ise düşüktür. Sonuç olarak RTF ile kestirim ortalamada kabul edilebilir değerler türetmiş olsada bu farklılık lokal ölçekte sapmalara neden olmuştur.

\section{Sonuçlar}

$\mathrm{Bu}$ çalışmada bir demir yatağında maden kaynak kestiriminde geleneksel olarak kullanılan krigleme yöntemi ile RTF temelli kestirim yöntemi kıyaslanmıştır. Krigleme yöntemiyle kestirim için öncelikle deneysel variogramlar hesaplanmış ve model variogramlar uyarlanmıştır. Buna göre variogram yapısal uzaklığı yatay ve düşey yönde sırası ile $150 \mathrm{~m}$ ve 9 m'dir. Bu durum bir anisotropiyi göstermektedir. Uyarlanan variogram modeli kullanılarak krigleme ile kestirim yapılmıştır. Kriglemeyi takiben RTF ile kestirim gerçekleştirilmiştir. RTF ile kestirimde alfa değeri 2,6 olarak belirlenmiştir.

Krigleme sonucunda blok model ortalama tenör değeri \%31,22 olarak hesaplanmıştır. RTF ile kestirimde ise blok model ortalamas $\% 29,98$ 'dir. Her iki kestirim de kompozit ortalamas1 olan \%30,96'ya oldukça yakındır. Bu açıdan her iki kestirimin de yansız olduğu söylenebilir. RTF ile kestirimde en yüksek ve en düşük değerler sırası ile $\% 55,88$ ve $\% 12,05$ 'tir. Krigleme aralıkları ise en yüksek ve düşük değerler için sırası ile $\% 44,66$ ve \%18,27'dir. Bu bakımdan RTF ile kestirimin kriglemeye göre daha geniş aralıkta sonuç ürettiği söylenebilir. Bu durum kestirimde istenen bir durum olup ileri aşamalarda yani maden rezerv kestirimi ve planlamasında daha gerçekçi sonuçların ortaya koyulmasında faydalı olacaktır.

Her iki yöntem için X, Y ve Kot yönlerinde trend analizleri yapılmış ve kompozitler ile karşılaştırılmıştır. Trend analizleri incelendiğinde her iki yöntemin de kompozitlere benzer sonuçlar ürettiği görülmüştür. Trend analizleri bakımından her iki yöntem de daha yumuşak değer geçişleri göstermiş̧lerdir. Bu davranış diğer interpolasyon yöntemleri ile paylaşılan bir fenomendir.

Sonuç olarak, RTF temelli kestirim, yöntemin doğası gereği istenilen aralıklarda kestirim sonuçları üretmektedir. Bununla birlikte Kriglemede olduğu gibi kestirim değerleri ortalamaya yaklaşmaktadır ve standart sapması ham verilerden düşüktür. $\mathrm{Bu}$ sebepten özellikle en düşük ve en yüksek kestirim değerlerinin ham verilere yakın çıkmasının istendiği durumlarda kullanılabileceği söylenebilir.

RTF temelli kestirimin uygulaması henüz kısıtlıdır. $\mathrm{Bu}$ zamana kadar RTF temelli kestirim ile ilgili yayın çalışmaları devam etmekle birlikte bu çalışma dışında Türkçe bir yayın bulunmamaktadır. Günümüzde kestirim yöntemlerinin yaygınlaşması büyük ölçüde bu yöntemlerin kullanıldığı maden tasarım destek programlarının varlı̆̆ına bağlıdır. Yöntemin yeni olmasından dolayı günümüzde henüz RTF temelli kestirimi bünyesinde barındıran bir tasarım destek programı yoktur. $\mathrm{Bu}$ sebepten yöntemin saha mühendisleri tarafindan uygulanabilirliği henüz kısıtlıdır. Sadece bu çalışmada kullanılmak amacı ile yazılmış bir MATLAB programı geliştirilmiş olsa da bu program henüz paylaşıma açık değildir. Ayrıca RTF ile kestirimde kullanılan parametreler deneme yanılma ile belirlenmektedir. Uzun ve zahmetli olan deneme yanılma yöntemi yerine bu parametrenin tahmin edilmesini kolaylaştıran yöntemlerin geliştirilmesi gerekmektedir.

\section{Teșekkür}

Makalenin hazırlanması esnasında yapıcı eleştirileri ile yayını zenginleştiren hakemlere teşekkür ederiz.

\section{Kaynakça}

Afzal, P. (2018). Comparing ordinary kriging and advanced inverse distance squared methods based on estimating coal deposits; case study: East-Parvadeh deposit, central Iran. Journal of Mining and Environment, 9(3), 753-760.

Bargawa, W. S., Nugroho, S. P., Hariyanto, R., Lusantono, O. W., ve Bramida, R. F. (2020). Geostatistical Modeling of Ore Grade In A Laterite Nickel Deposit. LPPM UPN "Veteran" Yogyakarta Conference Series Proceeding on Engineering and Science Series (ESS), 1(1), 301-310.

Bargawa, W. S., ve Tobing, R. F. (2020). Iron ore resource modeling and estimation using geostatistics. AIP Conference Proceedings, 2245(1), 70016.

Cornell, R. M., ve Schwertmann, U. (2003). The iron oxides: structure, properties, reactions, occurrences and uses. John Wiley ve Sons.

Dag, A., ve Ozdemir, A. C. (2013). A comparative study for 3D surface modeling of coal deposit by spatial interpolation approaches. Resource Geology, 63(4), 394-403.

De-Vitry, C., Vann, J., ve Arvidson, H. (2007). A guide to selecting the optimal method of resource estimation for multivariate iron ore deposits. Proceedings of the Iron Ore 
Conference, 67-77.

Elevli, B., Demirci, A., Dogan, A., ve Onal, G. (2018). Resource and reserve analysis of Hasancelebi Iron Ore deposit, Turkey. Mine Planning and Equipment Selection 2000, 199.

Gül, Y., ve Küçükkarasu, O. (2020). Resource estimation for Alpagut-Dodurga coal field and determination of spatial distribution of coal quality parameters. Turkish Journal of Earth Sciences, 29(3), 521-537.

Gusman, M., Muchtar, B., Syah, N., Akbar, M. D., ve Deni, A. V. (2019). Estimations of limestone resources using three dimension block kriging method, a case study: limestone sediment at PT Semen Padang. IOP Conference Series: Earth and Environmental Science, 314(1), 12069.

Hatton, W., ve Fardell, A. (2012). New discoveries of coal in Mozambique-Development of the coal resource estimation methodology for International Resource Reporting Standards. International Journal of Coal Geology, 89, 2-12.

Jeuken, R., Xu, C., ve Dowd, P. (2020). Improving Coal Quality Estimations with Geostatistics and Geophysical Logs. Natural Resources Research, 1-18.

Journel, A. G., ve Huijbregts, C. J. (1978). Mining geostatistics (C. 600). Academic press London.

Marwanza, I., Nas, C., Azizi, M. A., ve Simamora, J. H. (2019). Comparison between moving windows statistical method and kriging method in coal resource estimation. Journal of Physics: Conference Series, 1402(3), 33016.

Matheron, G. (1963). Principles of geostatistics. Economic geology, 58(8), 1246-1266.

Myers, D. E. (1992). Kriging, cokriging, radial basis functions and the role of positive definiteness. Computers ve Mathematics with Applications, 24(12), 139-148.

Nielsen, S. H. H., Partington, G. A., Franey, D., ve Dwight, T. (2019). 3D mineral potential modelling of gold distribution at the Tampia gold deposit. Ore Geology Reviews, 109, 276289.

Rossi, M. E., ve Deutsch, C. V. (2013). Mineral resource estimation. Springer Science ve Business Media.

Samanta, B. (2010). Radial basis function network for ore grade estimation. Natural resources research, 19(2), 91-102.

Santos, T. C. dos, ve Yamamoto, J. K. (2019). Ore resource estimation based on radial based functions-Case study on União Luiz and Morro do Carrapato Gold Deposits (Alta Floresta Gold Province). REM-International Engineering Journal, 72(3), 493-499.

Shahbeik, S., Afzal, P., Moarefvand, P., ve Qumarsy, M. (2014). Comparison between ordinary kriging $(\mathrm{OK})$ and inverse distance weighted (IDW) based on estimation error. Case study: Dardevey iron ore deposit, NE Iran. Arabian Journal of Geosciences, 7(9), 3693-3704.

Siddiqui, F. I., Pathan, A. G., Ünver, B., Tercan, A. E., Hindistan, M. A., Ertunç, G., Atalay, F., Ünal, S., ve Killıŏglu, Y. (2015). Lignite resource estimations and seam modeling of Thar Field, Pakistan. International Journal of Coal Geology, 140, 84-96.

Skala, V., Karim, S. A. A., ve Cervenka, M. (2020). Finding points of importance for radial basis function approximation of large scattered data. International Conference on Computational Science, 239-250.

Tercan, A. E., ve Karayigit, A. I. (2001). Estimation of lignite reserve in the Kalburcayiri field, Kangal basin, Sivas, Turkey. International Journal of Coal Geology, 47(2), 91-100.

Tutmez, B., Dag, A., ve Cengiz, A. K. (2009). Measuring dependence between calorific values of lignite and spatial positions by rank correlation method: A case study. Energy Sources, Part A: Recovery, Utilization, and Environmental Effects, 32(1), 45-53.

Wadi, M., ve Ivanik, O. (2019). Geospatıal Modellıng And Reserves Estımation Of Wad1 Al Shatı Iron Ore Deposit (Libya). Monitoring 2019, 2019(1), 1-5.

Wang, J., Zhao, H., Bi, L., ve Wang, L. (2018). Implicit 3D modeling of ore body from geological boreholes data using hermite radial basis functions. Minerals, 8(10), 443.

Wang, S., Li, X., ve Du, K. (2017). Grade distribution and orebody demarcation of bauxite seam based on coupled Interpolation. Arabian Journal for Science and Engineering, 42(9), 3963-3972.

Whateley, M. K. G., Inaner, H., Nakoman, E., ve Mulcahy, S. (1997). Comparison of classical and geostatistical methods for coal resource estimation in the Turgut Deposits, MuğlaYatağan, SW Turkey. European Coal Geology, Proceeding 3rd European Coal Conference, 559-572.

Wright, G. B. (2003). Radial basis function interpolation: numerical and analytical developments. $\mathrm{Ph}$. D. Thesis, University of Colorado, $183 \mathrm{p}$.

Yaylagul, C., ve Tutmez, B. (2020). Learning distance effect on lignite quality variables at global and local scales. International Journal of Coal Science ve Technology, 1-13.

Yünsel, T Y. (2007). Maden yataklarının jeoistatistiksel yöntemlerle analizi ve modellenmesi. ÇU Fen Bilimleri Enstitüsü, Maden Mühendisliği ABD, PhDr Tezi, Adana.

Yünsel, T. Y. (2019). In-situ coal quality variability analysis by combining Gaussian co-simulation and a JavaScript. Energy Sources, Part A: Recovery, Utilization, and Environmental Effects, 41(21), 2631-2649.

Zerzour, O., Gadri, L., Hadji, R., Mebrouk, F., ve Hamed, Y. (2021). Geostatistics-Based Method for Irregular Mineral Resource Estimation, in Ouenza Iron Mine, Northeastern Algeria. Geotechnical and Geological Engineering, 1-10.

Zhang, S. E., Nwaila, G. T., Tolmay, L., Frimmel, H. E., ve Bourdeau, J. E. (2021). Integration of machine learning algorithms with Gompertz Curves and Kriging to estimate resources in gold deposits. Natural Resources Research, 30(1), 39-56.

Zhang, S. wen, Shen, C. yang, Chen, X. yang, Ye, H. chun, Huang, Y. fang, ve Lai, S. (2013). Spatial Interpolation of Soil Texture Using Compositional Kriging and Regression Kriging with Consideration of the Characteristics of Compositional Data and Environment Variables. Journal of Integrative Agriculture, 12(9), 1673-1683. https://doi.org/10.1016/S2095-3119(13)60395-0 